\title{
Political Economy and the roots of Rawls' original position ${ }^{1}$
}

\author{
Fabrício Pontin \\ fpontin@gmail.com
}

Southern Illinois University, Illinois, USA

abstract The impact and relevance of economic theory to the development of "A Theory of Justice" are often left aside in the immense literature regarding the works of John Rawls. And yet, understanding the elements of political economy in Rawls' work is fundamental for the comprehension of why Rawls' will abandons a utilitarian approach to political philosophy and, consequentially, for our understanding of the main issues that motivate the notion of Justice as Fairness. This article has two mains goals: First, to describe the influence of John Stuart Mill, Kenneth Arrow and Vilfredo Pareto in the methodological turn found in the idea of the Original Position; and second, to describe the historical elements that are presupposed for the conceivability of Rawls' ideals. I conclude the present paper with some remarks suggesting a historicist and phenomenological complement to the ideal descriptions found in political liberalism as understood by Rawls.

keywords Political Economy; Political Liberalism; Original Position; Rational Choice

In 1929 Wittgenstein presented, in Cambridge, a lecture on ethics. This would be the only time the author would dedicate his focus to the topic. The article indicates the immense difficulty in establishing a language in which one can deal with ethics and value constitution. The "running against the boundaries of our cage" ${ }^{2}$ described by Wittgenstein hides a peculiar concern: could statements about ethics ever be the case? That is, could they ever be considered true or false? This takes us back to the question of what allows us to say that an object "q" has properties "z," "y" or "a" that permits us to speak of that object as "q," and should those properties cease to be the case for "q", then "q" will no longer be the case 
at all.Very well, when dealing with physical objects or with facts of nature, such statements of "case" might be, at least prima facie, easier to denote. It is true that Force equals Mass times Acceleration, it is true that a body in rest will remain at rest until something disturbs its condition, and it is true that the blackness of the keyboard in which I type this text is the result of an interaction of light waves that travel at an approximate velocity of $3.0 \times 10^{8} \mathrm{~m} / \mathrm{s}$. But these statements are reproducing laws of physics, and we have a particular language in which to deal with these laws - granted, this is also an imperfect language, but even with this proviso in mind, one is hard pressed to find a hypothesis in which we will note that the inertia is not the case. Now, what can we say regarding value-like judgments?

If the German and French tradition focused on speculative conditions for moral theory and the connection between the moral and the legal, English and American modernism is marked by a sharp focus on economics. Perhaps this is an acknowledgment of the limits of moral theory: since we cannot quite grasp the processes of value constitution and identity, we could focus on how we establish preferences and how these preferences result in dynamics of exchange of value. It also recognizes that the constitutional organization of societal dissent becomes an irresistible trend in European politics after the Westphalia Peace - and such constitutional organization brings with it the bureaucratic organization of Capitalism.

In that sense, Rawls is right, in $1974^{3}$, when he decides to focus on the elements of Political Economy in Utilitarianism in order to build his critique of comparative-advantage models of political philosophy. The motivation for this focus is twofold: first, the acknowledgement that after the recognition of the prevalence of Rights, the debate on which values should be considered universal is no longer controversial ${ }^{4}$; second, after the emergence of the liberal doctrine of rights, economic theory is the only sort of comprehensive doctrine that needs to be argued in political terms: again, the focus is on how Rights should be implemented and not why ${ }^{5}$.

It is no coincidence that Rawls builds much of his reflections on the presuppositions built by Pareto and later by Arrow ${ }^{6}$. It was Arrow that was able to proof that Pareto's complex system for a social equilibrium was possible, at least mathematically, in a plane. But he was also able to point at mathematical discrepancies in the general development of a democratic system. That is, even in very minimal conditions, it was nearly impossible, 
from the standpoint of political economy, to assert a mathematically sound form for a democratic system.

Now I want to develop the conditions, from the standpoint of political economy, which will allow Rawls to develop a methodological core for his defense of liberal politics. Rawls describes the processes of social choice and preferences leading to the development of liberal societies. Such description is operative on the basis of rational choice theory and utilitarian theory, which Rawls attempts to overcome in his account of a Universalist, principle-based, description of the prevalence of Rights.

In this sense, we must understand which elements of Economic Theory are fundamental for the development of Rawls' magnus opus. Tackling such elements will allow us to identify the main issues found by Rawls on utilitarian theory. Such issues, it seems to me, are not of philosophical, but rather economical origin.

As far as Political Economy is concerned, the entire debate on preferences circles around a single idea developed by Stuart Mill: the notion of "The Decided Preference Criterion". On the fourth chapter of his masterpiece Utilitarianism, Mill anticipates the further two hundred years of debate on Rational Choice in a simple succession of statements about preferences. First, Mill suggests that it is possible to prefer one pleasure over another.Then, that if one pleasure is perceived as in higher order than another, it is reasonable to assume that individuals that experience these pleasures of a higher order will seek activities and experiences that lead to this pleasure. And will, of course, avoid activities and experiences that will cause the desired pleasure to stop, or that will cause it to disappear. Also, it is possible to prefer to avoid means to a certain pleasure (even of a higher order) if circumstances would cause such discomfort that the obtained pleasure would be, in context, meaningless. In that sense, if I really enjoy lemon ice cream, I will seek experiences that lead me to lemon ice cream - rather than chocolate ice cream, which I loathe. However, if circumstances would have me tortured, or have me killing babies by throwing them against a wall, or have me eating chocolate ice cream so I could have lemon ice cream, then it is perfectly reasonable to prefer not to have lemon ice cream.

Now, the key point for the possibility of even conceiving of such pleasures is that individuals are able to develop "habits of self-consciousness and 
self-observation" "This means that a decision on preferences, particularly on higher-order preferences, must be a somewhat informed decision, that is, individuals that decide on preferences are making decisions with some degree of consciousness on the causal chain that lead from an experience onto a pleasure, and that they are able to understand at least some of the more intricate subtleties of such causal chain. Furthermore, Mill trusts that people have preferences because they have preferences. That is, they are only marginally affected by external factors and circumstantial advantages (though, as I have mentioned, there is a proviso for certain means for an end that could imply suffering or discomfort of a higher order than the order of the preference in view).

\section{a) Some examples of Pareto Efficiency in choice}

Before moving further, I want to clarify some aspects of Pareto Efficiency. First of all, we must understand that Pareto Efficiency has two possible scenarios to deal with; on the one hand we have a scenario where a dominant strategy is given such as actors that choose can have their best desired choices given to them (or at least conceive of these possibilities in a plane). On the other hand, we have scenarios where a dominant strategy is not given in such a way, as the best desired choices are not conceivably available for actors.

So, let there be two actors choosing fruits, where 100 is favorite, 50 is acceptable and 0 is unacceptable

Actor one values

a) Grapes - 100

b) Grapefruit -51

c) Lemmon -1

Actor two values

a) Lemmon -100

b) Grapefruit -51

c) Grapes -1

Now, evidently in all cases where one and two are choosing independently of each other and have all three possibilities given to them without any sort of interference, they will independently choose (a) and grant their highest pleasure. This is a max-max scenario. 
However, given a plane where individuals are choosing scarce goods such scenarios is a bit different.

Let there be a scenario where different possible choices are given to actors $\mathrm{A}(\mathrm{x})$ and $\mathrm{B}(\mathrm{y})$

\begin{tabular}{|l|l|l|l|}
\hline & & \multicolumn{2}{|c|}{ B } \\
\hline & & 1 & 2 \\
\hline \multirow{2}{*}{$\mathrm{A}$} & 1 & 100,1 & 50,50 \\
\cline { 2 - 4 } & 2 & 50,1 & 1,100 \\
\hline
\end{tabular}

In that case, it is feasible that individuals will opt out of their most preferred choice (100) so that they won't hurt the available choices for (B). This is a Weak Pareto Efficiency. That is, individuals in a plane can choose feasible states.

This presupposes that individuals will not act in an egotistical way to grant his own best pleasure disregarding putting others in a worst-off situation. For Pareto the management of resources becomes a key factor here to avoid civil unrest (but this is a different discussion altogether).

Hence, for all sets of possibilities where $\{a, b, c\}$ are given for actors as possible choices, a Pareto efficiency will tell us that the reasonable choice (for 1 and 2) is preferring (b), as moderate choices are more likely to lead to efficient outcomes as:

$$
\begin{aligned}
& a-b<b-c \\
& -2 b<-a-c \\
& b<a / 2+c / 2
\end{aligned}
$$

Now, as we increase the number of social states and social choices, the board here will get more and more complex. Also, this situation supposes a scenario of unforced equilibrium (that is, both parts can get a feasible social state). This is what we call a max-mini scenario. An interesting feature of this scenario is that in terms of social choice it implies that actors can have better outcomes (in the long run) by choosing preferences that are less desirable in their own ranks (that is, acting in a selfish manner can be a trait of economical irrationality). 


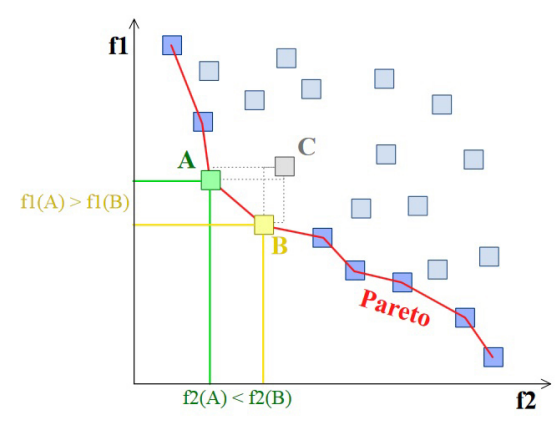

The graph above offers an example of such a scenario. Given that the blocks are possible choices, most of the equilibrium points between (f1) and (f2) will be in the lower end of the spectrum. Now, observe that two of these available states are desirable for both (f1) and (f2) and are hence "optimum" in max-mini terms. Other points can be a point of equilibrium, in economic terms (that is, there is enough of these goods for both actors), but the choice of these goods would imply one of the actors to be "worse off" than the other one in the end of the process of choice. This point of equilibrium is the core of Rawls' difference principle ${ }^{8}$.

Pareto also conceives of similar scenarios where such distribution of commodities is not feasible. In that case, the efficient point is the point where the least bad favorable set of choices is made available for the biggest number of actors in the choice plane. This is dubbed, in economics, a bliss point, also, a mini-max scenario.

Finally, a last scenario is given in the plane where all the available goods are terrible or goods are unavailable (think of post-war Germany, Japan, and Vietnam). This would be a mini-mini scenario.

In a mini-max and in a mini-mini scenario a Pareto Efficiency is impossible. Given that a Pareto Efficiency is dubbed a principle of economical rationality in most of post-war literature, any scenario as such them becomes an undesirable point, or, if you prefer, an irrational system of distribution.

\section{b) An economic theory of democracy}


Arrow, under heavy influence of Pareto, will attempt to further control the elements in Mill's criterion for choice. First of all, he will hold that having a preference only means that one is able to express a hierarchy of values or of choices in accordance to two general principles of connectivity and transitivity ${ }^{9}$. Having a preference, then, means to be able to (A1) express a hierarchy and (A2) hold the internal coherency of the hierarchy of values ${ }^{10}$. It is very important to note that Arrow does not care for the motivations behind the process of achieving a preference. What matters here is that an individual can and will express a consistent set of preferences. This is true to the way in which we decide on our favorite flavors for ice cream, or on our favorite candidates in an election. Any rational actor, for Arrow, will remain consistent in her options. Take, for example, when one says that one prefers Lemon to Orange and Orange to Mellon, it will necessarily follow that one will prefer Lemon to Mellon (by A2). This is, of course, a very weak notion of rationality ${ }^{11}$ insofar it only asks of an actor to maintain a minimal consistency in her own expression of preferences.

But how do we move from individual ranking of preferences onto a social ranking of preferences?

Arrow will name "the social welfare function"12 the process by which individual preferences are represented in an election. Voters will be able to decide on a number of commodities (objects of choice) that will constitute a social state (a conceivable set of commodities) which represents individual orderings of preferences. The social welfare function is such that the set of orderings $(\mathrm{R})$ of different voters will be taken in consideration so that for any two social states $\mathrm{x}$ and $\mathrm{y}$ of a given social ordering $\mathrm{R}$ will be given ${ }^{13}$.

The social welfare function operates in this manner regardless of individual expressions of any sort of preferences. The rule overrides individual preferences in accordance to the general will. Now, I realize the dangers of suggesting that Arrow is following a classic conception of general will, but in fact, once we analyze the conditions in which the social welfare function operates, it will become more and more clear the extent to which Arrow is relying on a classical-liberal notion of democracy.

For Arrow, we must first ask what are the conditions that satisfy the form of a democratic system? If we could organize the criteria according 
to which we think through democracy, what would be the general set of rules that would need to be followed in order for an election to be called democratic, or for the establishment of social welfare?

Arrow's dissertation Social Choice and Individual Values ${ }^{14}$, holds that a (and perhaps any) plausible definition of Democracy is incomplete. This means, in the terms first developed by Godel, that the set of requirements established in order to reach a conclusion that " $p$ is the case" end up causing that " $\sim p$ is the case." The act of voting is important here because it is the moment in which individuals choose for a certain set of social preferences that are represented in a candidate or in a policy. If there is something fundamentally paradoxical in the act of voting, then the entire idea of a democracy will fall to pieces, after all, even direct modes of representation still presuppose the existence of some sort of election.

On the one hand, it is sufficient, for Arrow, that individuals are expressing their individual preferences in accordance to criteria of transitivity and connectivity. On the other hand, he super-imposes a number of conditions of reasonability for the achievement of an acceptable constitution (in this case, an acceptable election). So far, we know that the social welfare function will be as complex as the number of available social states, the multiplicity of chosen social states and the number of individuals.

Furthermore, the conditions in which individuals vote must be so that a set of "control criteria" are met.

(C1) Non-dictatorship (ND): The social welfare function should account for the wishes of multiple individuals. It cannot simply mimic the preferences of a single individual.

(C2) Universality (U): For any set of individual voter preferences, the social welfare function should yield a unique and complete ranking of societal choices. It must do so in a manner that results in a complete ranking of preferences for society (by A1) and it necessarily provides the same ranking each time voters' preferences are presented the same way (by A2)

(C3) Independence of Irrelevant Alternatives (IIA): Irrelevant alternatives cannot impact on relevant alternatives. That is, a change in the expression of an irrelevant subset cannot influence the ranking of the relevant subset strategic movement of irrelevant values in order to affect relevant values is thus avoided as well as incompleteness in the relevant subset. 
(C4) Monotonicity (Mono): For all individual set of choices ' $r$ ' there will correspond a social ordering ' $R$ '. Any promotion in ' $r$ ' entails a promotion in ' $\mathrm{R}$ ' or, in the worst case, the repetition of the status quo ante. A promotion in ' $r$ ' can never correspond to a decrease of the social ordering in ' $\mathrm{R}$ '. An individual should not have to vote against the proposal that he wishes to pass in order to promote it (by C2 and A2). In other words, values present in $\mathrm{r}$ will supervene in $\mathrm{R}$.

(C5) Non-imposition (NI): Individuals are free to decide their order of preference without external coercion. Any result is possible within the given set in the beginning of an election, and any given ranking is possible within the set. The social welfare function has an unrestricted space within the set of possible alternatives.

In theory, Pareto had indicated that any distribution of goods, in a plane, always means that the gain of an individual (or social group) causes another individual (or social group) to lose. In that sense, processes of exchange would never be a situation, where parties could benefit equally. Except given the conditions for a free and informed process of exchange, where parties could express and negotiate their preferences with minor interference, leading to a mark wherein the gain of an individual would not cause other individual to lose. Pareto expressed the plausibility of the notion of the "invisible hand" of the market which would be able to mitigate the processes of social loss and gain in a hypothetical equilibrium.

Arrow was able to demonstrate that such an ideal position, dubbed "the first principle of Welfare economics," was mathematically possible in a plane, given that individuals were indeed in a situation of "perfect information" 15 and that certain conditions for the ranking of preferences were present. Such criteria for choice are the same that I analyzed above, and the same that led, even given very narrow criteria for reason and rationality in choice, to paradoxical scenarios regarding the Social Welfare Function ${ }^{16}$. Note that Arrow's conditions for choice are the same conditions that Pareto developed for his idea of efficiency, and are, for Arrow, equivalent to a Reasonability criteria ${ }^{17}$.

In this sense, the social welfare reproduces individual preferences indirectly even though they are expressed directly, it also avoids that irrelevant issues become decisive in the definition of a Social Welfare Function. Arrow will not justify his principles of democratic order to a great extent. His main 
contention is that they "seem to be sound" and that they fit the modern interpretation of what a democracy requires to be called a democracy. Note that neither of these conditions is sufficient alone for a democratic system. They are all together necessary for a sufficient conception of Democracy - and note that this sufficient conception of Democracy looks very much like a constitutional democracy such as the one we will find as the basic structure for institutional fairness later in Rawls.

This is mostly because individuals will not act without aiming at individual benefit, even at the expense of others, without some sort of regulatory mark or safety net. In a system of unequal opportunities and unequal preferences, individuals will not choose in a well-ordered, previously expected, manner, just to submit to the elegance of Arrow's mathematical notations ${ }^{18}$. Perhaps this is why Arrow himself focused on elements of value in the end of his dissertation, noting that some sort of ethical "guideline" is necessary for the "soundness" of the democratic proposition $^{19}$.

\section{c) Utility calculation and Justice as Fairness}

It seems to me that it is at this point that Rawls sees the limits of utilitarian ${ }^{20}$ theory and decides to focus on a Kantian approach to political theory. Given only the elements of utility calculation we will not reach, in Rawls, the scenario in which we could build a reasonable Social Welfare Function. But it is clear that without Arrow, Rawls could not have developed his idea of original position, nor could have him noted the conditions for principles of justice. ${ }^{21}$

But I think it is important to emphasize that the doctrine of liberalism is first and foremost understood by Rawls, at least in A Theory of Justice, as a method. This means that ideals like the original position, reflective equilibrium and considered moral judgments are, at first, not understood as a matter of fact, but rather nominal conditions for a particular doctrine of liberalism that Rawls wishes to advance.

The idea of the original position starts from a shared suspicion among modern philosophers against personal experience as a justification for the expression of political priorities. It seems that Rawls wants to take the 
procedure of de-personalization, invented by Kant in the development of the Categorical Imperative, as a procedure for validity of conduct, even further. After all, the original position requires not only that parts go further than their sensible motivations for conduct would take them, it actually requires that parts act as if their sensible motivations for conduct, their personal history and so on, were actually never the case.

This hypothetical exercise would then put individuals in a situation where former "prejudices" or "judgments" on conduct, former experiences are left at the door when individuals enter the procedure for a rational choice of values for a social welfare function. Why so? This has two main reasons; on the one hand, we have Rawls' trust in the Kantian proviso that reason alone, that is, a speculative use of reason, could give a framework of which values matter. On the other hand, Rawls relies deeply on insights from economic theory.

The notion of an original position is then a requirement for the soundness of the reflective equilibrium in a social welfare function and the reflective equilibrium is a mirror image of the idea of the aforementioned Pareto's equilibrium, that is, the point where in an exchange would not necessarily imply a situation where the benefit of an individual (or group) in a social welfare function will not cause other individual (or groups) in a social welfare function to be worst off ${ }^{22}$.

Now, I want to ask how individuals in the original position look like. Granted that Rawls stresses the hypothetical character of the position, and that it belongs in the realm of ideal theory, I believe the question remains valid: what do the hypothetical individuals in the hypothetical original position look like?

Will individuals in the original position be aware of the potential consequences of their choices for values, and will they have knowledge about future conditions, for example, in order to know that not suffering from starvation is preferable to suffering from starvation, and hence policies and principles that will avoid starvation are preferable to policies and principles that will lead some people to starvation but might get other people rich beyond their wildest dreams?

In that case, is it really sound to say that individuals in the original position are dropping their considerations about current social reality when they reach the situation wherein they are making social choices? 
I realize this is all somewhat counter-intuitive if we follow a canonic interpretation of what Rawls is proposing. In a purely charitable interpretation, it should suffice to conceive of a possible position where individuals will somewhat intuitively know that minimal conditions for social justice are preferable to conditions for social injustice.

It is that sense that I insist that, in heart, $A$ Theory of Justice is dealing with a method for political theory in its first part, and this method deals with the conditions where in the ideal social welfare function of a liberal society is possible. Part of this core supposes that individuals will intuitively prefer not to feel pain, rather than to feel pain; that they will prefer values that will potentially grant more rather than less freedom. The other and perhaps less persuasive part of the method, deals with a sort of abandonment of the current social reality when one is conceiving of these preferences. For Rawls, this is a fundamental move in order to erase prejudices and potential advantages that individuals might have been "polluted" with when developing their current value judgments. Considered value judgments will then be justified when they are valid within the scope of the Original Position, and will potentially conduct society to a position of reflective equilibrium, that is, a position wherein the expression of individual preferences for one policy or one plan of life is not potentially harmful to the possible expression of other individual preferences.

The key adjective for Rawls, then, quickly becomes "reasonable," and reasonable is synonymous with the intuitive considerations hypothetical individuals are able to justify from the standpoint of a hypothetical original position. Clearly, Rawls still believes in the powers of speculative reason and of the possibility of detaching value considerations from social contingencies when doing so. As far as ideal theory goes, this is pretty far in the Kantian spectrum of the board - but Rawls believes that the actuality of the Kantian thesis is supported by what political economy tells us about potential collaboration and competition among individuals in an exchange model.

However, the model proposed by Pareto and adopted by Rawls presupposes conditions for the processes of choice: it presupposes a number of ideal situations and ideal individuals that are necessary for the establishment of a certain position of ideal exchange of values. It also 
presupposes that individuals are not under stress of previous experiences when they are making "reasonable" choices about their preferences.

These are, of course, awfully heavy presuppositions.

Rawls knows this, and it is not a coincidence that the second part of A Theory of Justice is a heavy treatise on the importance of an institutional framework that will support individuals that will be able to choose in such a fashion. As a matter of fact, I believe that the second part of the book provides us with a historic account of how an ideal social-welfare function, from the standpoint of political liberalism, is possible. If we look at the methodological and deontological core represented by equal liberty, distributive justice and duties and obligations, we are looking at the history of the formation of the modern State, and it is within this modern State, that clearly takes shape in the constitutional revolutions in the United States, France and England, that Rawls sees the potential for a realization of his project.

This would answer the question "who are the individuals in the hypothetical original position": the individuals that are in the end of the process of secularization and emancipation represented in the rise of the modern State.

This means two things: first, it means that a modern, liberal, State is intuitively preferable to a non-modern, non-secular, State. Mostly because the conditions wherein a reasonable social welfare function is possible are only present in current and actually existent modern States. The other, is that this movement, because of its intuitive necessity, is defensible for States that are not yet modern, and that individuals in these States will move towards a more liberal and more secular position of rights - given the opportunity to do so.

The second part of the argument is found in the universal claims about moral personality, or potential moral personality, in the third part of Rawls' treatise: when we deal with the importance of the good, the sense of justice and the role of justice, we are dealing, at least according to Rawls, with features that are shared universally by human beings. Rawls main thesis is difficult to argue against: The ideals of freedom of speech and equal opportunity may very well be historical contingencies, peculiar to western cultures and with a dark and complex history. Still, our reasons to implement these Rights are sound, and we have no reason 
to believe that others would not want to have these same rights, that they do not share our moral sentiments insofar they relate to fundamental principle of justices (freedom from bondage, equal opportunity among individuals, open possibilities for plans of live, etc.) The question is then one of increasing the reach of such rights: If the doctrine of modern philosophy created an unprecedented increase in the quality of life in the circumstances where those principles were effectively implemented, then why should we not attempt to implement such principles in a larger scope? In this sense, the liberal thesis becomes irresistible in Rawls.

\section{d) Towards a historic-phenomenological critique of choice}

It is interesting to note that the approach suggested by both Arrow and Rawls has no shortage of mentions to "ideal types." I do not think that the use of an "ideal" structure for the election, voting process and the conditions of democracy altogether, is a coincidence. As a matter of fact, Arrow and Rawls are both profoundly Weberian when they try to establish a mode in which an ideal structure is feasible. Note that Arrow will say that individual preferences are somehow present in social choices, and Rawls reminds us of Weber a great deal when he writes that values and ideals are reasonable insofar they can be justified by members of a society, at the same time that they are not really empirical.

However, to the best of my knowledge, Rawls only mentions Weber once in A Theory of Justice The mention is hidden in the end of the book ${ }^{23}$, in a footnote, where Rawls accuses both Weber and Max Scheler (as far as I know, this is the only time Max Scheler is mentioned by Rawls) of providing a stratifying and stiff notion of vocation that does not allow for social change or mobility, and that does not explain changes in social motivation and preferences.

And yet, without a non-static conception of time there is hardly any chance we will make sense of how preferences come to be the case. There is a whole set of expectations and representations that are taken for granted in the moment of decision. We constitute values in relation to our past, to our society, to our heritage. Does that mean that one created in a racist background will always be a racist? Not at all. But this 
background will participate a great deal in the way that this individual will, for example, resist racism and constitute his own perspective on how and why racism is wrong. In that sense, the reality of values for individuals or group is socially constructed, and not built from scratch according to the desire of the philosopher.

In this sense, even strategic motivations must be put in context, as well as the interaction that marks such strategy. Why is it that my attitude towards others leads me not to trust their ability to collaborate or to share a determined set of values with me?

By focusing on the institutional determination of ideal types, we might take the social interaction for granted and ignore an important aspect of the "equation," that is: the constitution of ideal types is necessarily connected to the historical construction of these ideal types. The process of signification of the structure of a cultural phenomena or an ideal conception is a result of a historical struggle which is connected to a number of interpretations of the phenomena and the ideal, this means that there is no institutional ideal type that is not in an interaction with subjects, and that there are no subjects that are outside of interaction as they conceive on an ideal type. Of course, in doing so we are already moving outside the grounds of a Weberian historicism and moving towards a phenomenological structuralism.

If we are able to recognize the importance of a reflective equilibrium between ideal principles of justice that are decided in a representative form, and a moral pedagogy that informs the decisions about conceptions of good. We must also understand that these processes are not static, nor are they always given in the same way or in the same environment. Reflecting this multiplicity of conceptions and the conflict of these conceptions is precisely what is at stake for the written form of a legislation that aims to enforce sociability among different individuals - and different socializations that come incarnate with these.

1 Technical revision by Jessica Soester ( $\mathrm{PhD}$ Candidate, Southern Illinois University, Carbondale)

${ }^{2}$ WITTGENSTEIN. Lecture on Ethics. Available at http://sackett.net/WittgensteinEthics. pdf (Last access 8/28/2012) 
${ }^{3}$ RAWLS, John. A Theory of Justice. (1974, repr. Cambridge: Harvard University Press, 1999).

4 “"[j] ustice as fairness holds that, with regard to the constitutional essentials and questions of basic justice, and given the existence of a reasonably well ordered constitutional regime, the family of basic political values expressed by its principles and ideas have sufficient weight to override all other values that may normally come into conflict with them". RAWLS, Justice as Fairness: a restatement, p. 183. Also "From the standpoint of moral theory, the best account of a person's sense of justice is not the one which fits his judgments prior to his examining any conception of justice, but rather the one which matches his judgments in reflective equilibrium “. RAWLS, $A$ Theory of Justice, p. 43

${ }^{5}$ Ibid, p. 185

${ }^{6}$ Note that the entire development of the terms for the two principles of Justice in A Theory of Justice (p. 52-86) is based on the debates on distribution equilibrium in political economy. This debate is only made possible by Pareto's reflections (A Theory of Justice, p. 58n) on fair distribution of goods.

${ }^{7}$ RAWLS. Lectures on the History of Political Philosophy, p. 260.

${ }^{8}$ RAWLS. A Theory of Justice, p. 152

${ }^{9}(\mathrm{x}, \mathrm{z})$ are candidates, $\mathrm{P}=$ preference, $\mathrm{I}=$ indifference, $\mathrm{R}=$ preference or indifference in context. Connectedness: For all (the objects of choice in the set) $\mathrm{x}$ and $\mathrm{y}$, either $\mathrm{x} \mathrm{R} y$ or $\mathrm{y} \mathrm{R}$ $\mathrm{x}$. (A1); Transitivity: For all x, y, and $z, x R y$ and $y R z$ imply xRz. (A2). Thus, alternation ('or') and conjunction ('and') of $\mathrm{R}$ relations represent both the properties of an ordering for all the objects of choice. In this sense, the possibilities of ordering preferences will be so defined: D1: $\mathrm{xPy}<_{-}>\sim(\mathrm{yRx})$ (by A1) ; D2: xIy <-> \{xRy and yRx) (by A2); D3: xRy <-> $\sim_{\mathrm{yPx}}$

${ }^{10}$ ARROW. A difficulty in Social Welfare. In: ARROW. The collected papers of Kenneth J. Arrow, Vol. I: Social Choice and Justice, p. 26-7

${ }^{11}$ See ARROW. Current Developments in the Theory of Social Choice. In: ARROW. The collected papers of Kenneth J. Arrow, Vol. I: Social Choice and Justice, p. 163

${ }^{12}$ ARROW. Social Choice and Individual Values,p. 22-33

13 For Arrow: $\mathrm{xPy}$ is "social preference" of $\mathrm{x}$ over $\mathrm{y}$ ( $\mathrm{x}$ is selected over $\mathrm{y}$ by the rule); $\mathrm{xIy}$ is "social indifference" between $\mathrm{x}$ and $\mathrm{y}$ (both are ranked the same by the rule) and $\mathrm{xRy}$ is either "social preference" of $\mathrm{x}$ over y or "social indifference" between $\mathrm{x}$ and $\mathrm{y}$ ( $\mathrm{x}$ is ranked at least as good as y by the rule).

${ }^{14}$ ARROW, Kenneth J. 1963. Social Choice and Individual Values. New Haven:Yale University Press.

${ }^{15}$ A perfect information situation is one where individuals are aware of the possible set of preferences available for all other individuals in a plane. In game theory, this means that all possible moves of all players in the field are visible for all the players in the field (and players in the field have a similar understanding of the set of rules for the game). In economic theory this means that parts are aware of the risks and implications of their moves, and are able to move freely towards their preferable states or goods. Arrow is aware of the artificiality of this situation, but it is mathematically possible to conceive of such state, and this is enough for the viability of Pareto`s equilibrium - at least from an Economical standpoint. 
${ }^{16}$ The peculiarities of the so-called "paradox of voting" can be found in Arrow's dissertation Social Choice and individual Values.

${ }^{17}$ As a matter of fact, Arrow was part of the team of economists that demonstrated the possibility of Pareto's Equilibrium.

${ }^{18}$ Thus, for example, the necessity of the difference principle in Rawls. (see RAWLS. Justice as Fairness: $A$ re-statement, p-158-9).

19 See the important of a social ordering of minimal preferences, or social consensus, in Arrow's Social Choice and Individual Values, $\mathrm{p}$ 81-6. This is connected to the importance of a collective rationality that will serve as a "control" for self-interest and manipulation in the democratic process. Arrow is clearly uncomfortable when dealing with these issues, and most of his insights on the matter are vague and will only be fully explored in Rawls' appropriation of Pareto's equilibrium as a Reflective equilibrium.

${ }^{20}$ Arrow prefers to call his theory an Ordinalist rather than Utilitarian theory. This is a result of what he considers a major re-appropriation of Mill's notion of utility and choice. For Arrow, his preference criterion is a weaker, more modest, elaboration of Mill's Decision criteria, one that relies on a minimal requisition for decision efficiency: transitivity and connectivity. In Arrow`s view, this is no longer utilitarian in the sense coined by Mill, it is rather Ordinalist, in the sense that it equals reason with choice-efficiency. If a choice is efficient (transitive and connected), then it is a rational choice (ARROW. Some Ordinalist-Utilitarian notes on Rawls'Theory of Justice. In:ARROW. The collected papers of Kenneth J. Arrow, Vol. I: Social Choice and Justice, p. 98). Interestingly, Arrow thinks his notion of Ordinalism is overall compatible with Rawls' position. This should not be surprising, given that Rawls also adopts the model of Pareto's equilibrium for his Reflective equilibrium, and that both rely heavily on the notion of perfect information (though in a different way, as we will further see).

${ }^{21}$ Compare, for example, the summarization of the Difference Principle in p.61- 3 of $A$ Theory of Justice and its importance for a "system of cooperation" with what I have just analyzed in Arrow and Pareto. Also note that this entire discussion is operative on the terms introduced by Mill in his Political Economy and Utilitarism.

${ }^{22}$ See the paragraph 16 of A Theory of Justice, and p. 65 in Justice as Fairness.

${ }^{23}$ TJ: 479(n). Weber returns, however, in Justice as Fairness, p154n29, in an important footnote dealing with the inevitability of "loss" and human tragedy in the rise of new economic organizations.

\section{Bibliography}

1983. Collected Papers of Kenneth J. Arrow, Volume I: Social Choice and Justice. Cambridge: Harvard University Press, 1983. 1984. Collected papers of Kenneth J. Arrow, Volume IV:The Economics of Information. Cambridge: Harvard University Press, 1984. 
1996. Political Liberalism. New York: Columbia University Press, 1996.

.1999. A Theory of Justice. Cambridge: Harvard University Press, 1999. 2003. Justice as Fairness, $A$ restatement. Cambridge: Harvard University Press, 2003. .2008. Principles of Political Economy. New York: Oxford University Press (USA)., 2008

ARROW, Kenneth J.1963. Social Choice and Individual Values. New Haven:Yale University Press, 1963.

BERGER, Peter L; LUCKMANN, Thomas. 1967. The Social Construction of Reality. New York: Doubleday \& Company, 1967.

MILL, John Stuart. 2002. Utilitarianism. Indianapolis: Hackett Publishing Company, 2002.

PARETO,Vilfredo.2007. Considerations on the Fundamental Principles of Pure Political Economy (Routledge Studies in the History of Economics). Routledge: London, 2007.

RAWLS, John. 2007. Lectures on the History of Political Philosophy. Cambridge: Harvard University Press, 2007.

RAWLS, John;, FREEMAN Samuel (ed). 1999. Collected Papers. Cambridge: Harvard University Press, 1999.

WEBER, Max; HEYDEBRAND, Wolf (ed).1994. Sociological Writings. New York: Continuum, 1994.

WITTGENSTEIN, Ludwig. Lecture on Ethics. Available at http://sackett. net/WittgensteinEthics.pdf (Last access 8/28/2012) 